Prepared for the U.S. Department of Energy

under Contract DE-AC05-76RL01830

\title{
US Renewable Futures in the GCAM
}

SJ Smith

JF Karas
AH Mizrahi

M Nathan

October 2011

\section{Pacific Northwest}

NATIONAL LABORATORY

Proudly Operated by Battelle Since 1965 



\title{
DISCLAIMER
}

This report was prepared as an account of work sponsored by an agency of the United States Government. Neither the United States Government nor any agency thereof, nor Battelle Memorial Institute, nor any of their employees, makes any warranty, express or implied, or assumes any legal liability or responsibility for the accuracy, completeness, or usefulness of any information, apparatus, product, or process disclosed, or represents that its use would not infringe privately owned rights. Reference herein to any specific commercial product, process, or service by trade name, trademark, manufacturer, or otherwise does not necessarily constitute or imply its endorsement, recommendation, or favoring by the United States Government or any agency thereof, or Battelle Memorial Institute. The views and opinions of authors expressed herein do not necessarily state or reflect those of the United States Government or any agency thereof.

\author{
PACIFIC NORTHWEST NATIONAL LABORATORY \\ operated by \\ BATTELLE \\ for the \\ UNITED STATES DEPARTMENT OF ENERGY \\ under Contract DE-AC05-76RL01830
}

Printed in the United States of America

Available to DOE and DOE contractors from the

Office of Scientific and Technical Information,

P.O. Box 62, Oak Ridge, TN 37831-0062;

ph: (865) 576-8401

fax: $(\mathbf{8 6 5}) \mathbf{5 7 6 - 5 7 2 8}$

email: reports@adonis.osti.gov

\author{
Available to the public from the National Technical Information Service, \\ U.S. Department of Commerce, 5285 Port Royal Rd., Springfield, VA 22161 \\ ph: (800) 553-6847 \\ fax: (703) 605-6900 \\ email: orders@ntis.fedworld.gov \\ online ordering: http://www.ntis.gov/ordering.htm
}

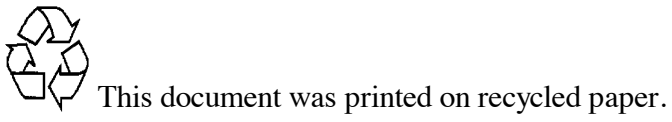

$(9 / 2003)$ 

PNNL-20823

\section{US Renewable Futures in the GCAM}

Steven J. Smith

Andrew Mizrahi

Joseph Karas

Mayda Nathan

October, 2011

Prepared for the U.S. Department of Energy

under Contract DE-AC05-76RL0

Pacific Northwest National Laboratory

Richland, Washington 99352 



\begin{abstract}
This project examines renewable energy deployment in the United States using a version of the Global Change Assessment Model (GCAM) with a detailed representation of renewables, the GCAM-RE. Electricity generation was modeled in four generation segments and 12-subregions. This level of regional and sector detail allows a more explicit representation of renewable energy generation. Wind, solar thermal power, and central solar PV plants are implemented in explicit resource classes with new intermittency parameterizations appropriate for each technology. A scenario analysis examines a range of assumptions for technology characteristics, climate policy, and long distance transmission. We find that renewable generation levels grow over the century in all scenarios. As expected, renewable generation increases with lower renewable technology costs, more stringent climate policy, and if alternative low-carbon technologies are not available. The availability of long distance transmission lowers policy costs and changes the renewable generation mix.
\end{abstract}




\section{Contents}

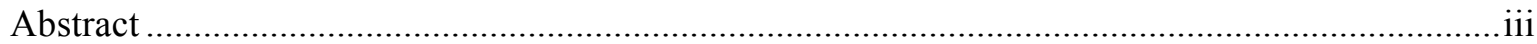

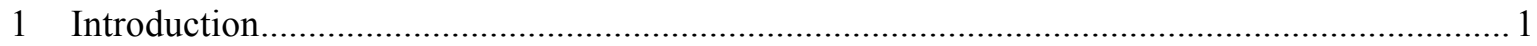

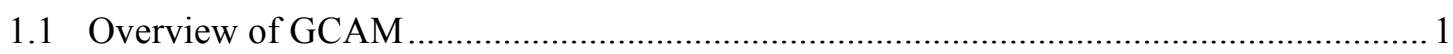

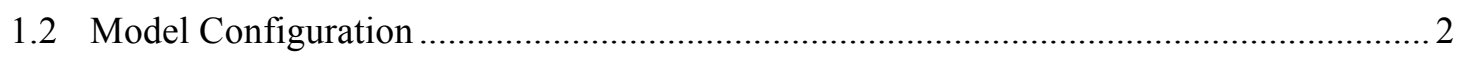

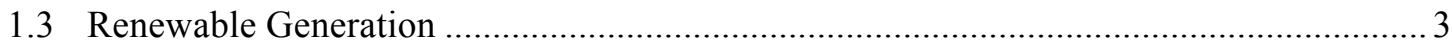

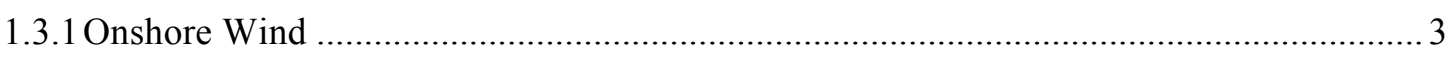

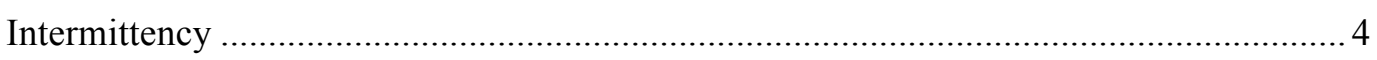

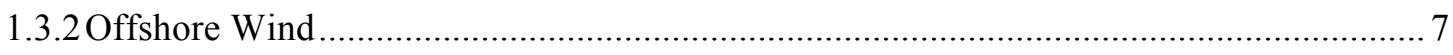

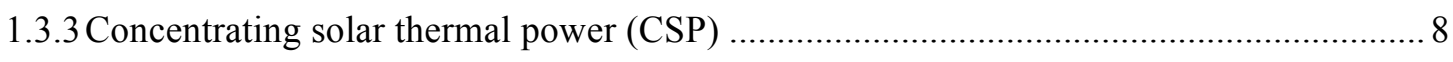

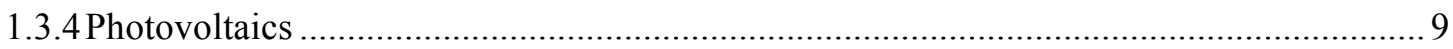

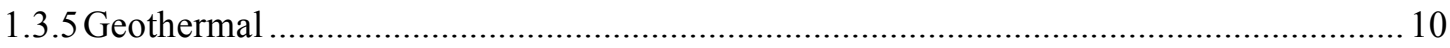

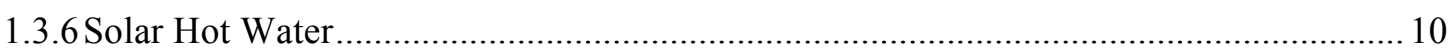

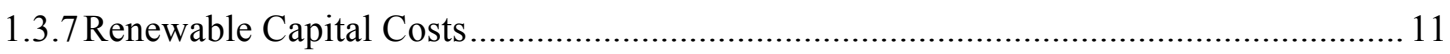

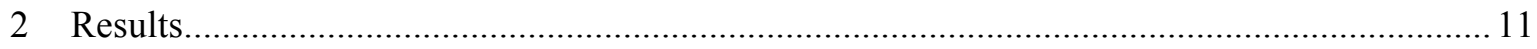

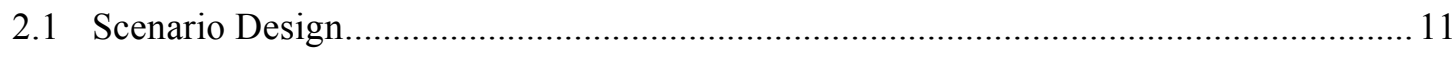

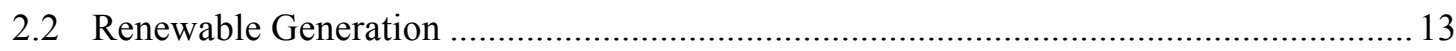

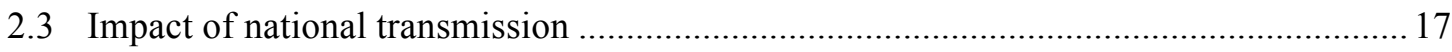

2.4 Renewable Generation and Climate Policy Costs....................................................... 18

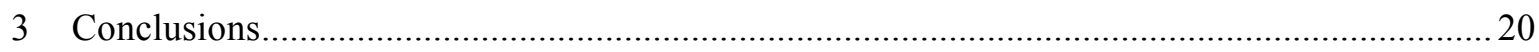

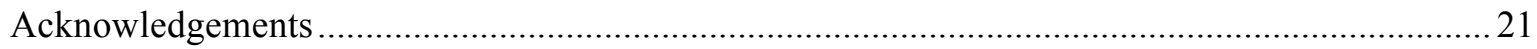

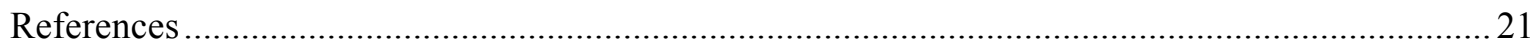




\section{Introduction}

This report documents the modeling approach and an overview of results from a detailed study of renewable energy in the United States using a research version of the Global Change Assessment Model (GCAM-RE). GCAM-RE contains a detailed representation of renewable energy supply for the United States embedded within the GCAM, a global, integrated assessment model of energy, agriculture, land use, and climate change.

\subsection{Overview of GCAM}

The analysis for this paper was conducted using the GCAM-RE, which is based on the GCAM 2.0 integrated assessment model (Brenkert et al., 2003; Kim et al., 2006). GCAM is a dynamic-recursive, partial-equilibrium model that links representations of global energy, agriculture, land-use, and climate systems. GCAM runs in 15-year timesteps from 1990 through 2095, and has 14 regions, one of which is the United States. While the present study focuses on dynamics within electricity supply sectors, the model calculates equilibria in each time period in all regional and global markets for energy goods and services, agricultural goods, land, and, where applicable, greenhouse gas (GHG) emissions. GCAM-RE contains detailed representations of wind, solar PV, solar CSP, and solar hot water.

Exogenous model inputs include service demand drivers (population and economic growth), exhaustible and renewable resource supplies, and characteristics of technologies involved in the production, transformation, delivery, and final consumption of energy. Multiple technologies may compete to provide any energy good or service, and market share is allocated to competing technologies on the basis of relative costs, using a logit choice mechanism (Clarke and Edmonds, 1993). The cost of each technology is calculated as the sum of levelized capital and O\&M costs and fuel or resource costs. Capital and O\&M costs are exogenous, and fuel costs are calculated from exogenous efficiencies and endogenous fuel prices. In the case of geothermal energy, the costs are calculated based on a combination of regional, exogenous supply curves that represent "resource" costs and technology. Model assumptions for scenario variables and technologies not investigated in this study can be found in Clarke et al. (2008a).

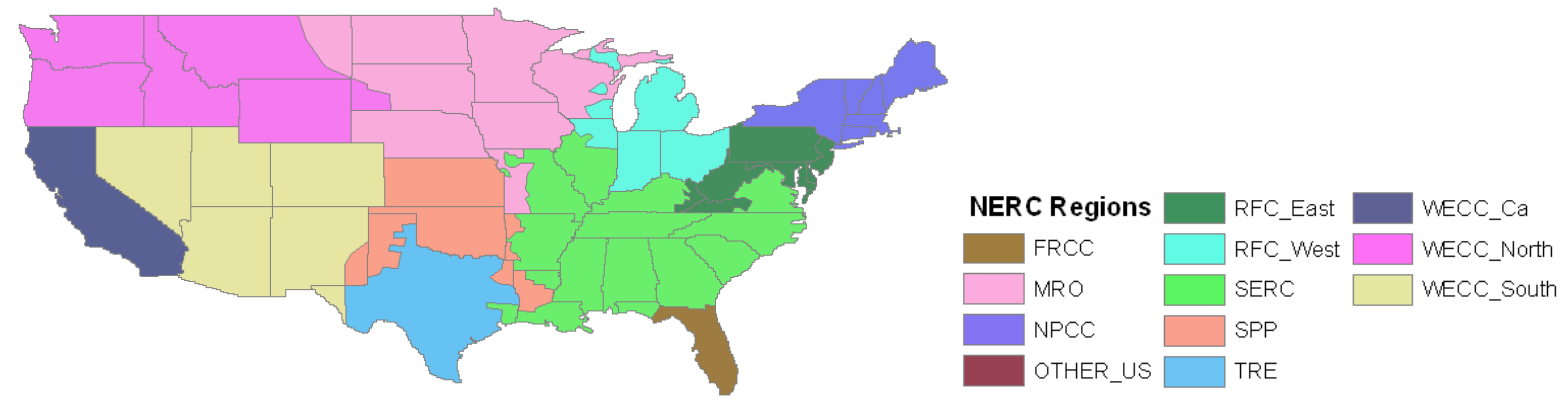

Figure 1. U.S. sub-regions used to break-out regional electricity generation. 


\subsection{Model Configuration}

For the analysis conducted in this project, the model was configured with 12 sub-regions, as illustrated in Figure 1. Sub-regions generally followed NERC region boundaries, with some larger NERC regions sub-divided to better capture regional heterogeneity. Within each subregion, four electricity generation segments were implemented (Wise and Smith 2007: base load, intermediate, sub-peak, and peak (Figure 2). We find that four segments are sufficient to capture the overall dynamics of electricity supply and demand over an average year. The segments are defined by the number of generation hours they contain in a load-duration curve. Fossil-fuel technologies are assigned to these segments based on average capacity factors. Base load plants have the highest capacity factors, with generation in this segment favoring plants with low fuel costs, with higher capital costs tolerated since this can be amortized over a larger number of operating hours. Peaking plants, in contrast, might operate a few hours a day for a few weeks a year. Operation under these conditions favors low capital costs, even if fuel costs are higher due to lower efficiencies.

A general translation between the operational categories used here and seasonal/time of day operation is as follows: base load technologies represent plants that operate in all seasons and around the clock. Most coal-fired and all nuclear power plants are base load plants. Intermediate load plants operate during the daytime through early evening. In the U.S., natural gas plants are often used for this segment. Sub-peak plants might operate only a few hours a day in most seasons, if at all, and all day in summer-peaking regions. Peaking plants in warm regions will operate on hot summer days, during afternoon through early evening. Natural gas and oil-fired turbines have traditionally been used for this purpose.

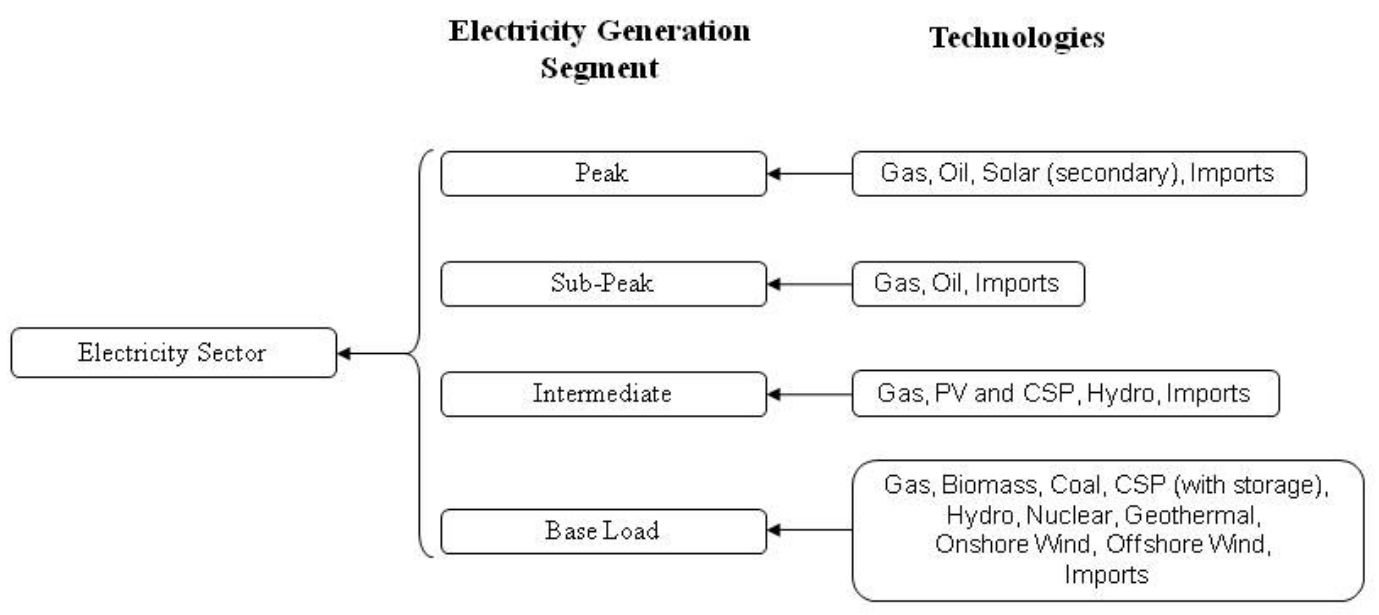

Figure 2. Electricity generation segments. 


\subsection{Renewable Generation}

Fossil-fuel and nuclear power plants can, in principle, be located where convenient (although often adjacent to a source of water for cooling) with fuel transported, usually over long distances, to the plant. Most renewable technologies have the opposite character; generation must be located at the location of a suitable resource, and the resulting product, such as electricity, must then be transmitted to load centers. Further, for many renewable technologies, generation can vary by time of day and season, an attribute often described as intermittency. Representation of renewable resources within energy-economic models must take these attributes into account.

Renewable generation within each sub-region was calibrated in 1990 and 2005 to EIA statelevel generation data, with generation pro-rated by population for states that cross NREC regions. Because this project was focused on renewable generation, and in order to simplify model set-up, generation for non-renewable resources was not calibrated at the sub-region level. Instead, non-renewable generation in each region used the average U.S. generation distribution as a starting point.

Each renewable technology supplies electricity to one or more electric load segments. Renewable generation does not always fit neatly into categories defined in terms of capacity factor. The GCAM currently treats geothermal and wind as base load technologies (as wind plants operate in all seasons; see below). CSP thermal and PV plants are treated as intermediate technologies, with an option for some contribution to peak and sub-peak. Additional demand can be met if electricity storage is paired with PV. Future CSP plants with large amounts of thermal storage can contribute to base load generation (Zhang and Smith 2007). Rooftop PV will compete with grid-produced electricity for supplying electricity to buildings, with its higher levelized costs offset to some degree by the fact that it incurs no transmission and distribution costs or energy losses.

In the default model configuration used in this study, we account for regional differences in renewable resources by representing renewable generation in 12 U.S. sub-regions. Renewable generation within each sub-region is assumed to be available to serve loads within that subregion. While we also incorporate the additional transmission cost of connecting wind or CSP solar plants to the grid, we do not model any additional transmission investments that might be needed to augment transmission grids within a sub-region to accommodate additional renewable generation. We consider inter-regional renewable transmission as an explicit grid scenario, as described below.

\subsubsection{Onshore Wind}

Wind generation is represented as a set of wind resources and wind technologies, following Kyle et al. (2007). Wind resources are characterized in terms of area, distance to grid, and wind speed. The wind resource data are derived from the 50-meter wind resource map developed by the U.S. Department of Energy's (DOE) Wind Program and the National Renewable Energy 
Laboratory (NREL) ${ }^{1}$. Wind data are processed by wind class to produce a resource curve in terms of available area as a function of distance to the transmission grid.

Not all windy land can be used for power generation. Wind resources are excluded based on land-use, land-cover, population density, and an overall landscape scale constraint. Wind resources are processed to exclude protected areas, waterways (including buffer areas), and half of Department of Defense (DoD) and national forest lands. Forested areas are excluded except for an allowance for $25 \%$ of forested land with class 5 and above winds (used to represent ridge top lands). An exclusion based on population density was also applied to simulate limits on turbine placement due to visual and noise impacts. A progressively increasing exclusion starts at 5 people per $\mathrm{km}^{2}$, with no turbine placement allowed at population densities above 325 people per $\mathrm{km}^{2}$. Finally, we assume that no more than $50 \%$ of the land in any half-degree grid cell can be used for wind turbines, which is a simple approach to the "suitability factor" used in some wind resource estimates (Hoogwijk et al. 2004). This can be considered an intermediate assumption for land-suitability. The impact of land suitability assumptions is examined in more detail in other work in progress (Zhou et al., in preparation).

Wind generation is represented by a set of technology objects, one for each wind class (class $3-7)$. Wind turbines are represented as idealized Rayleigh-Betz (R-B) turbines, characterized by a turbine rating and blade diameter. The output from the ideal turbine is reduced by three factors: a de-rating that represents real world turbine performance, conversion and turbine interaction losses, and an availability fraction. Wind speed at hub height is estimated from the wind resource data using a power law relationship between wind speed and height.

\section{Intermittency}

Wind generation varies by time of day and location, although when averaged over large areas this variation is reduced. There are a number of consequences of this variation, including impacts on voltage stability, ramping rates for other generators, reserve requirements, and potentially dumped output. The implementation used in this study accounts for three effects: increased reserve margin requirements with penetration, increased dumped output at higher penetration levels, and changes in the net load shape as a function of penetration.

As described in Kyle et al. (2007), the representation used here assumes that at low penetration levels the existing reserve margin requirements are sufficient to handle periods of low wind. As more wind generation is used, the wind farm must supply additional reserve margin, modeled primarily as an additional capital cost (assumed to be combustion turbines). The functional form of this requirement is given by:

1 http://www.windpoweringamerica.gov/ 


$$
\text { AdditionalReserve }=\sqrt{\text { ReserveRequirement }^{2}+\sigma^{2} W^{2}}-\text { ReserveRequirement },
$$

where $\mathrm{W}$ is the amount of wind generation, ReserveRequirement is the normal amount of reserve required, and $\sigma^{2}$ is the variance in wind power output. As more wind power is used, the shape of the remaining load changes. This effect can be examined on a national basis by computing the residual load as a function of wind penetration using wind output on an hourly basis from a national wind dataset constructed by NREL ${ }^{2}$. For each hour of the year, the residual load is calculated as the national load curve minus wind generation. Wind penetration is measured as the fraction of the GCAM base load segment. As more wind is used the load curve shifts down.

US Residual Demand

As fn of gross wind generation (as fraction of GCAM baseload)

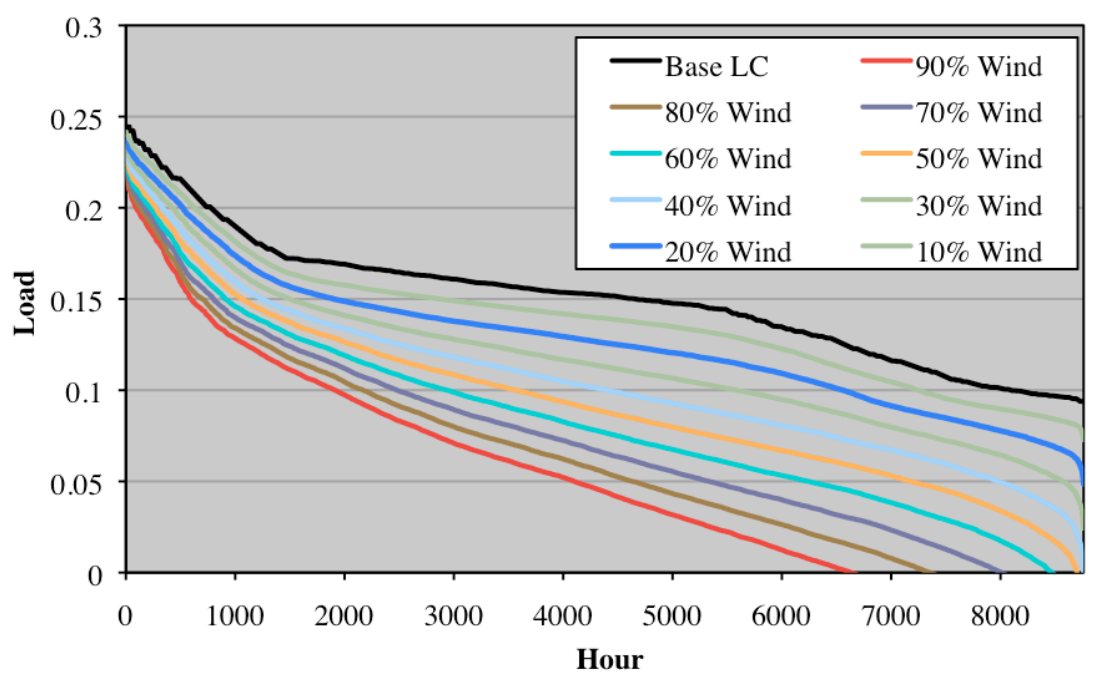

Figure 3. U.S. electricity demand after subtraction of wind generation.

From analysis of the residual load, several effects of increased wind penetration are apparent. First, the difference between the residual load and the original load curve occurs primarily in the base load segment as wind capacity increases (see Figure 3); this is demonstrated by the load curve somewhat uniformly shifting downwards with increasing wind penetration. This verifies that wind supplies primarily base load power. Second, at high wind penetration, wind output exceeds demand for some hours (particularly during nighttime). In Figure 3, this occurs for all cases above 50\% wind, where the residual demand reaches zero for some hours of the year. Without storage or sufficient system flexibility, this power must be dumped. This excess output only occurs when wind is supplying greater than about $50 \%$ of base load generation. Third, as wind penetration increases, the reduction in base load demand is larger than the amount of wind generation by about $10 \%$. The difference manifests primarily as an increase in demand in the sub-peak segment. The reason for this effect is that due to varying wind output at different hours

2 M. Mowers (NREL), personal communication. Wind output aggregated from $\sim 32,000$ onshore sites in NREL US wind data for 2005. 
and seasons, generation in the sub-peak segment must "fill in" to meet load. Therefore, this study represents this phenomenon as a shift in the load curve over time as more wind is used in the system.

The estimated dumped load (also known as curtailment) that occurs when wind generation exceeds demand is a lower limit to the amount of actual dumped load. Wind output would also need to be dumped if wind output were to exceed base load generation. This effect has been examined in the context of PV generation by Denholm and Margolis (2007a, b). Here, bounds are placed on this effect using the residual demand analysis shown above. Wind power might also be dumped due to transmission limitations. It might not be economic, for example, to build or upgrade transmission to handle relatively rare instances of maximum output from a remote wind farm. Dumped wind estimates from a variety of literature sources informed this exercise.

\section{Wind Curtailment}

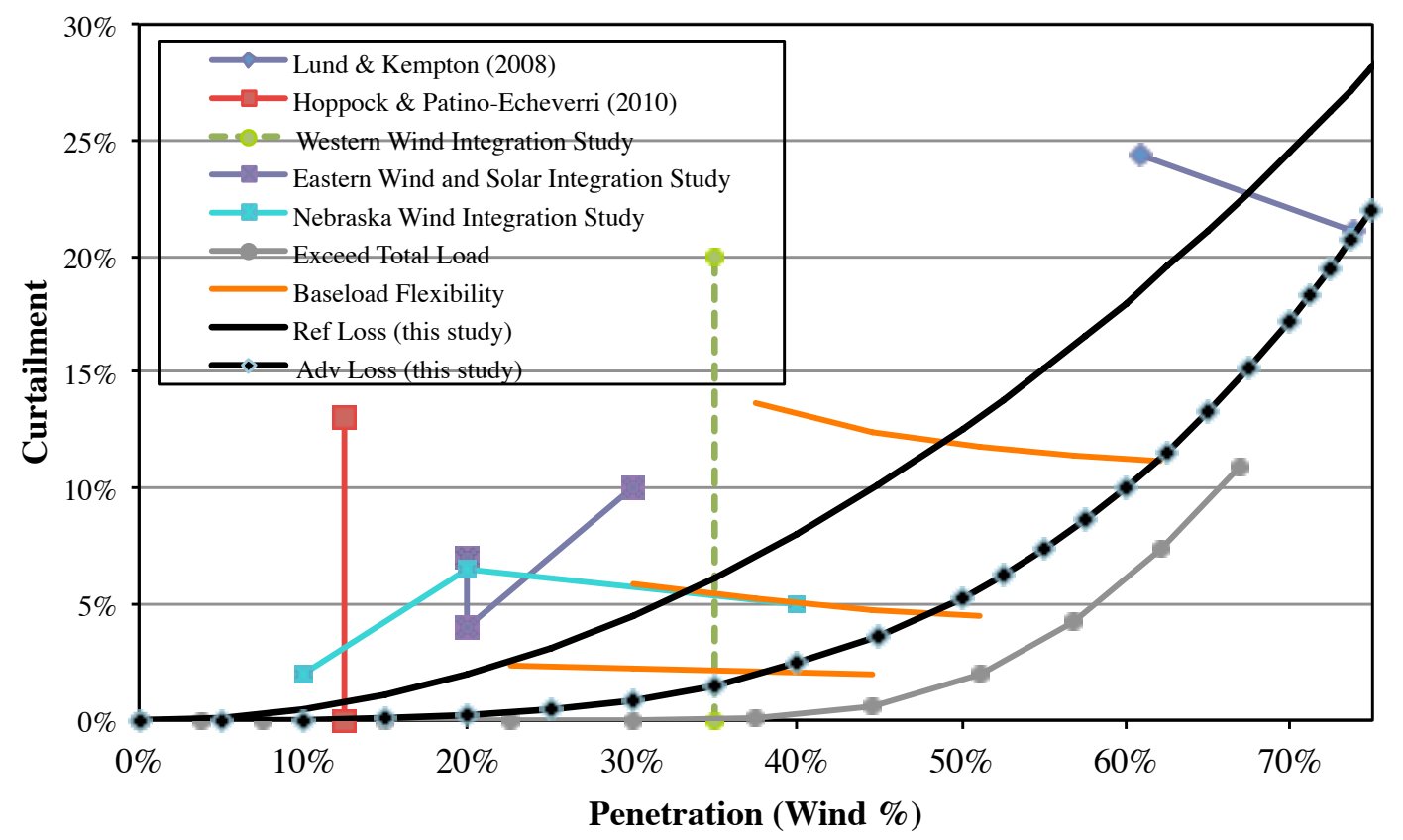

Figure 4. Wind curtailment: results from literature (including ranges from two studies) and present analysis and curtailment parameterization used in this study (black lines). Literature results shown are: Eastern Wind and Solar Integration Study (EnerNex Corporation 2010a), Nebraska Statewide Wind Integration Study (EnerNex Corporation 2010b), Western Wind and Solar Integration Study (GE Energy 2010), Hoppock, and Patino-Echeverri (2010), and Lund and Kempton (2008).

A graphical synthesis of the above analysis along with a summary of results from the literature is shown in Figure . Vertical lines indicate ranges found in a particular study (with the upper value generally representing an extreme value derived by assuming, for example, no new transmission construction). 
Two loss curves are derived. Dumped power in the Reference Scenario is about 5\% at 30\% penetration and increases to $10 \%$ at $50 \%$ penetration. The Advanced Scenario assumes more advanced grid and load management, and has a lower rate of dumped wind, reaching $5 \%$ at $50 \%$ penetration.

\subsubsection{Offshore Wind}

Offshore wind power is structured similarly to onshore wind, with individual base load technologies implemented for each wind class. Offshore wind contains an additional level of detail, with technologies and associated resources for three ocean depth categories: shallow, transitional, and deep water. Wind resources are characterized by available area as a function of distance to grid. In the case of offshore wind, the distance provided is the distance to shore - the distance over which expensive (relative to land-based transmission) underwater cable must be constructed to provide offshore wind power to the onshore electric transmission grid.

The cost of offshore wind is a combination of exogenous capital costs, an exogenouslyestimated cost of building underwater transmission lines, and technology performance parameters. Offshore wind capital costs are the sum of turbine costs and the additional costs related to collecting and transmitting power to shore, adjusted for a transmission loss percentage assigned to each depth. Offshore transmission losses are assumed to range from $4 \%$ for shallow to $7 \%$ for deep water, based on the average distance to shore for each depth class. The performance parameters are generally the same as for onshore wind farms.

The wind speed input data used are from UNEP's Solar and Wind Energy Resource Assessment project, collected by NREL. The QuikSCAT satellite estimates annual wind speeds at a height of $10 \mathrm{~m}$ by measuring ocean surface roughness. To estimate wind speed at $50 \mathrm{~m}$, power law exponents of 0.10 and 0.30 are used to adjust wind power and speed, respectively. Climatic conditions can cause the actual shear values to range from below 0.10 to above 0.15 for speed and 0.30 to 0.45 for power. These values also change seasonally.

NREL then averaged the data over the course of a five-year period (2000-2004) to obtain monthly averages of wind speed and power. Power is measured in $\mathrm{W} / \mathrm{m}^{2}$, given by:

$$
\text { Power }=0.5 \times \rho \times V_{w}^{3},
$$

where $\rho$ is the value of sea-level air density $\left(1.225 \mathrm{~kg} / \mathrm{m}^{3}\right)$, and $\mathrm{V}_{\mathrm{w}}$ is wind speed. If there were fewer than four observations for a cell in a given month, the data are excluded. The satellite measurements may vary from those taken by an anemometer. Annual wind speed accuracy is estimated to be $\pm 1 \mathrm{~m} / \mathrm{s}$. This uncertainty can result in a change of up to two power classes and a greater total speed range of $5-10 \mathrm{~m} / \mathrm{s}$. Instances of fewer observations and larger errors tend to occur in areas near coastlines and closer to shore. Note that the QuickSCAT satellite measures wind speed at two fixed times per day. A biased estimate could result if there is a strong diurnal wind pattern. 
Three water depth classes are used. Shallow water depth is $0-30 \mathrm{~m}$; in this class, the turbine tower structure is similar to those of onshore wind, though more costly. Transitional water depth is $30-60 \mathrm{~m}$, where a more extensive tower is necessary. Deep water is greater than $60 \mathrm{~m}$, where floating turbine platforms must be used. Water depth data from NOAA (ETOPO1 dataset) are used for determining areas for the three depth classes.

In this exercise, areas within nine kilometers (five nautical miles) of shore are excluded. Also excluded are two-thirds of the area between 9-40 km from shore, and one-third of more distant areas. Depths exceeding 200m are also excluded from the data. A recent EEA study (Europe's onshore and offshore wind energy potential; EEA 2009) assumes even more stringent limits, excluding $96 \%$ of area between $0-10 \mathrm{~km}, 90 \%$ between $10-50 \mathrm{~km}$, and $75 \%$ of the area beyond $50 \mathrm{~km}$. The impact of more stringent exclusion values could be examined.

There are several fixed costs that comprise the total capital cost of offshore wind:

$$
\text { CapitalCos } t_{\text {Offhorewind }}=\text { Turbine }+ \text { Collection \& Transmission }+ \text { Foundation }+ \text { BOS \& Fixed } .
$$

The turbine cost is the cost of the turbine and tower structure, and is assumed to be $10 \%$ greater than land-based wind turbines. The collection cable cost assumes a wind farm turbine spacing of $630 \mathrm{~m}$ and is based on the analysis of Green et al. (2007). Transmission cost is equal to the distance to shore multiplied by an assumed transmission cable cost, expressed in units of dollars $/ \mathrm{MW} / \mathrm{km}$. Transmission to shore can us AC technology for distances of around $80-100 \mathrm{~km}$. For greater distances, DC transmission must be used. Transmission costs are based on the average of the three cases reported in Green et al. (2007). The foundation cost is the cost of the base of the wind turbine structure. It is assumed that the foundation cost is higher in deeper water because the platform must be taller and more structurally complex. Deep water turbines must utilize a floating platform technology. Foundation costs are based on a combination of estimates from NREL (Musial and Butterfield 2004) and project data reported by Greenacre et al. (2010). Note that the shallow water foundation costs reported in Greenacre et al. (2010) are much higher than those in Musial and Butterfield (2004). An intermediate value is used here. The remaining costs are balance-of-system (BOS) and fixed costs, which refer to costs other than the turbine, cabling, and transmission - such as labor, electricity, and operation permits.

While it is possible that off-shore wind may have different temporal characteristics than onshore wind, analysis of the supply-duration curve for off-shore wind generation on the U.S. east coast from Lund \& Kempton (2008) finds a nearly identical behavior to the U.S. onshore data. Since a large portion of the U.S. wind resources is located off the east coast, we treat intermittency for offshore wind identically to onshore wind.

\subsubsection{Concentrating solar thermal power (CSP)}

Concentrating Solar thermal Power (CSP) plants are implemented using the methodology described in Zhang et al. (2010). For simplicity, this study assumes that only the highest quality 
solar resources are used for CSP. The CSP resource is taken to be land with the best resources, taken from the resource categories used in Zhang et al. (2010). Irradiance and the number of nonoperational cloudy days were estimated for each sub-region.

CSP plants are assumed to be operated as hybrid systems with natural gas or biomass backup boilers, thereby providing dispatchable power. Three configurations of CSP plants are implemented - CSP without thermal storage supplying intermediate power, CSP plants with four hours of thermal storage supplying intermediate power, and CSP plants with ten hours of thermal storage supplying base load power. A comparison of CSP output by season with a California load curve, for example, found that CSP plants operating as intermediate segment generators are a very close match to the state's seasonal intermediate load demand.

All CSP plants are assumed to make use of the hybrid backup system to produce power on cloudy days when the solar field is not operational (excluding scheduled maintenance). CSP plants operating as intermediate load plants also must use backup power at some time periods as CSP penetration increases (Zhang et al. 2010). Because CSP capital costs are assumed to fall over time, and natural gas costs often increase in GCAM scenarios (particularly under a carbon policy), backup costs can become a significant portion of total CSP levelized costs. The explicit representation of this interaction results in a more accurate representation of the potential role of CSP. CSP plants serving intermediate load also are subject to increasing dumped load as penetration increases, although for CSP plants with thermal storage this is small unless CSP is supplying a large fraction of intermediate power.

\subsubsection{Photovoltaics}

Photovoltaic (PV) technologies are implemented in two forms: as central PV generation plants and as distributed rooftop PV technologies. Rooftop PV is implemented in the building electricity distribution sector, where it competes with grid electricity to supply building electric loads using the supply curves for each sub-region from Denholm and Margolis (2008). Rooftop PV is more expensive than central PV installations, due to economies of scale and lower installation costs for central systems. Rooftop systems are assumed to compete against delivered electricity, which has a higher price as compared to the average generation cost seen by a central PV plant.

Central PV plants are implemented assuming an average irradiance value for each sub-region assuming systems tilted at latitude. The electric generation module includes representations of central PV with and without a dedicated electricity storage system.

A comparison of PV output with the California load curve by season, taken as typical of sunny regions, as well as analysis of the results from Denholm and Margolis (2007a), finds that while the largest portion of PV contributes to intermediate load, a portion of PV output offsets sub-peak and peak segments. Therefore, this study assumes that PV without storage contributes 
$25 \%$ of its power to the sub-peak load segment. PV with storage also contributes to peak and base load generation.

Intermittency is a substantial issue for PV power. This treatment of intermittency for PV draws from the analysis of Denholm and Margolis (2007a, b), who examine the impact of PV penetration in the Texas region. They find that dumped power becomes significant at penetration levels as low as $10 \%$ for PV systems without storage. PV systems augmented by electricity storage (or flexible generation response) can supply a greater fraction of load without dumped power. Therefore, a dumped power parameterization based on the Denholm and Margolis analysis is used for central PV systems. A backup requirement is also implemented such that, at high PV penetration levels, reliable power is provided during cloudy days.

\subsubsection{Geothermal}

Geothermal technologies are assumed to be base load technologies with no intermittency. Three geothermal technologies are implemented - hydrothermal, near-field hydrothermal engineered geothermal, and deep engineered geothermal (EGS). Geothermal technologies are implemented in the GCAM as described in Hannam et al. (2009), using updated resource and cost estimates from Augustine et al. (2010).

\subsubsection{Solar Hot Water}

Residential solar hot water is implemented as described in Smith et al. (2010), drawing on the methodology of Christensen and Barker (1998). Because solar hot water heaters can have natural gas or electric back-up, they can essentially be treated as high-efficiency natural gas and electric hot water technologies in residential buildings. As such, they are assigned an efficiency and non-energy service cost, representing levelized capital and O\&M costs of the systems. The "efficiency" used by the GCAM is technically an I-O (input-output) coefficient that represents the amount of energy input needed for a unit of service output (Smith et al. 2010). Solar hot water heaters' I-O coefficients are given by:

$$
C_{I-O}=\left(\frac{E_{S H W}^{a u x}}{E_{c o n v}}\right) \div \varepsilon_{c o n v}
$$

where the I-O coefficient (CI-O) is equal to the ratio of the auxiliary energy consumed by a solar hot water system ( $E_{S H W}^{a u x}$ ) to the energy consumed by a conventional hot water system (Econv), divided by the system efficiency of a conventional water heater ( $\varepsilon$ conv). These variables are specific to each sub-region, incorporating incident solar energy data from NASA, temperature differences between water mains and hot water tanks, and residential hot water draw (Smith et al. 2010). 


\subsubsection{Renewable Capital Costs}

The capital cost assumptions for renewable technologies are shown in the table below. Capital costs for most electric generation technologies have increased in recent years. The renewable costs below are based on literature reviews and recent assessments. Because the core GCAM model capital costs for non-renewable technologies are baselined to earlier, and lower, cost data the cost figures below were reduced by $20-25 \%$ in order to produce a level competition within the model. In general, the recent increase in power plant costs overall leads to substantial uncertainty in future costs. It is not clear, for example, how much of these recent cost increases might be temporary, or how much these reflect fundamental shifts in specific technologies or global cost structures.

Table 1. Capital Cost Assumptions.

\begin{tabular}{lcccccc} 
& \multicolumn{7}{c}{ Reference Tech } & Advanced Tech \\
Technology & 2005 & 2050 & 2095 & 2050 & 2095 & Units \\
\hline Onshore Wind (Class 7) & 1,278 & 1,099 & 1,045 & 720 & 657 & $2005 \$ / \mathrm{kW}$ \\
Offshore Wind (Shallow Average - Class 7) & 2,078 & 1,788 & 1,699 & 1,083 & 964 & $2005 \$ \mathrm{~kW}$ \\
CSP - Intermedite with Th Storage & 4,578 & 3,476 & 2,621 & 2,437 & 1,587 & $2005 \$ / \mathrm{kW}$ \\
CSP - Baseload (with Th Storage) & 5,410 & 4,092 & 3,070 & 2,813 & 1,800 & $2005 \$ \mathrm{~kW}$ \\
Central PV & 6,905 & 2,479 & 1,766 & 1,387 & 951 & $2005 \$ / \mathrm{kWpdc}$ \\
& 2,556 & 2,063 & 1,836 & 2,063 & 1,836 & $2005 \$ / \mathrm{kW}$ \\
Geothermal (Ca - hydrothermal) & - & - & - & 4,076 & 4,076 & $2005 \$ / \mathrm{kW}$
\end{tabular}

\section{Results}

\subsection{Scenario Design}

The goal of this study was to examine the role of U.S. renewable generation in the GCAMRE model. Three dimensions were examined: technology cost and availability, availability of long-distance transmission, and stringency of a climate policy target. The scenarios considered are shown in the table below.

Table 2. Roles of Renewable Generation in the GCAM-RE Model.

\begin{tabular}{|c|c|c|c|}
\hline $\begin{array}{c}\text { Renewable } \\
\text { Technology }\end{array}$ & Other Electric & Transmission & $\begin{array}{c}\text { Policy Target } \\
\left(\mathrm{W} / \mathrm{m}^{2}\right)\end{array}$ \\
\hline \multirow{3}{*}{ Reference } & Reference & Regional & None \\
& & Intermittency & 5.8 \\
& Mitigation & 4.5 \\
Advanced & No CCS/No New & National Renew & 3.7 \\
& Nuclear Sites & Grid & 3.0 \\
\hline
\end{tabular}

In the advanced technology scenarios, costs for renewable technologies were assumed to fall faster in the future as compared to the reference scenario. Wind dumped load was also assumed 
to occur at lower levels (Figure 4), and engineered geothermal generation is assumed to be available.

Two scenarios for other electric generation technologies are examined. In the first, there are no exogenous limits on any electric generation technology. A full suite of technologies compete, as appropriate, to supply electricity in the four generation segments. In the second scenario, Nuclear generation is limited to current levels and carbon-dioxide capture with geologic storage (CCS) is assumed to be unavailable. These can be considered bounding scenarios, with the first scenario perhaps overly optimistic, since not every technology will be suitable, or acceptable, in every region, and the second overly pessimistic.

The range of climate policy targets ranges from no climate policy, which is the reference case, to a very aggressive policy that meets a radiative forcing target of $3.0 \mathrm{~W} / \mathrm{m} 2$ by the end of the century. The policy cases are implemented in two stages. First, the GCAM-RE model is run with a global carbon tax which results in the end of century radiative forcing as indicated in the scenario name. Carbon dioxide emissions in the United States were then constrained to follow identical pathways for the alternative renewable technology and transmission cases. The global carbon price path associated with each scenario is applied to the rest of the world. This process was repeated for the set of scenarios without nuclear or CCS. These scenarios result in higher global and U.S. carbon prices. Carbon dioxide concentrations and U.S. emissions are shown in Figure 5.

Three transmission cases are considered. In the regional transmission case all wind, solar, and geothermal generation must be consumed within each U.S. sub-region. The national grid scenario adds an additional option whereby renewable generation can be consumed in any U.S. sub-region, although with an additional capital charge and transmission loss. The intermittency mitigation scenario examines the impact of changing the modeled constraints due to intermittency. The alternative transmission scenarios will be further described in the results section below.
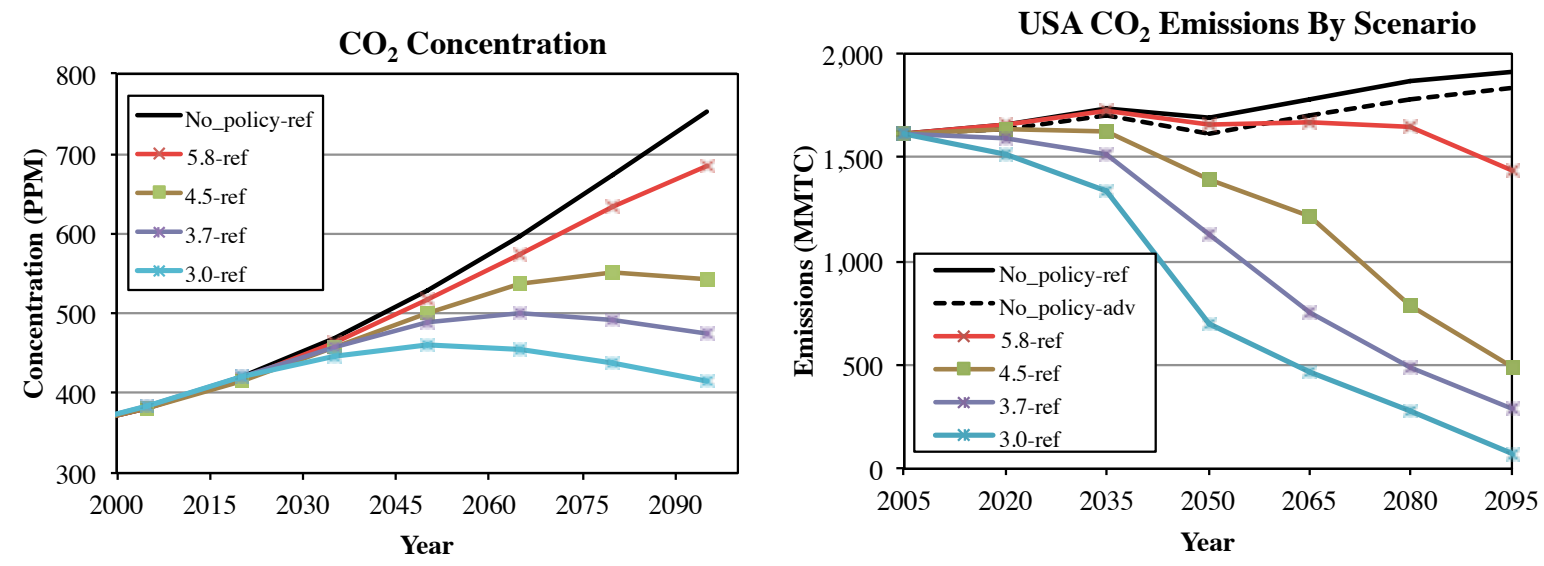

Figure 5. Carbon dioxide concentrations and carbon dioxide emissions pathways for the U.S. 


\subsection{Renewable Generation}

A common finding in IA models, including GCAM, is that the implementation of a comprehensive carbon policy spurs an increase in electricity demand. As electric generation decarbonizes, this spurs a shift in end-use sectors away from direct use of fossil fuels, which are now subject to a carbon price, toward electricity. This is shown in Figure 6, where electricity generation increases to slightly over 35 EJ by the 2095 .

\section{Total Electricity Generation (USA)}

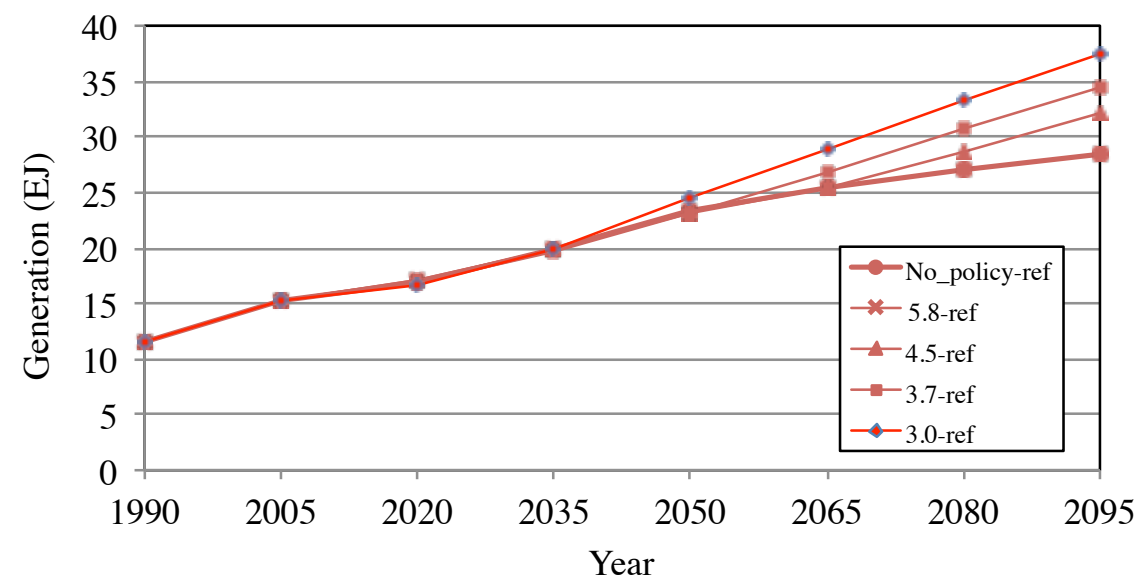

Figure 6. Total U.S. electricity generation for the reference case scenarios.

The cost of electricity generation increases over time, relative to the reference case due to a carbon policy. Costs for the reference case and the $4.5 \mathrm{~W} / \mathrm{m} 2$ scenario are shown in Figure 7. While under the reference case generation costs are fairly stable, costs are $20-40 \%$ higher under a carbon policy, relative to the reference case. Peak electricity costs increase the most, while costs for base load and intermediate generation show the smallest increase. This is because there are many more low-carbon options for base load and intermediate generation, while there are relatively limited options for the more flexible generation needed to provide peak and sub-peak power. 


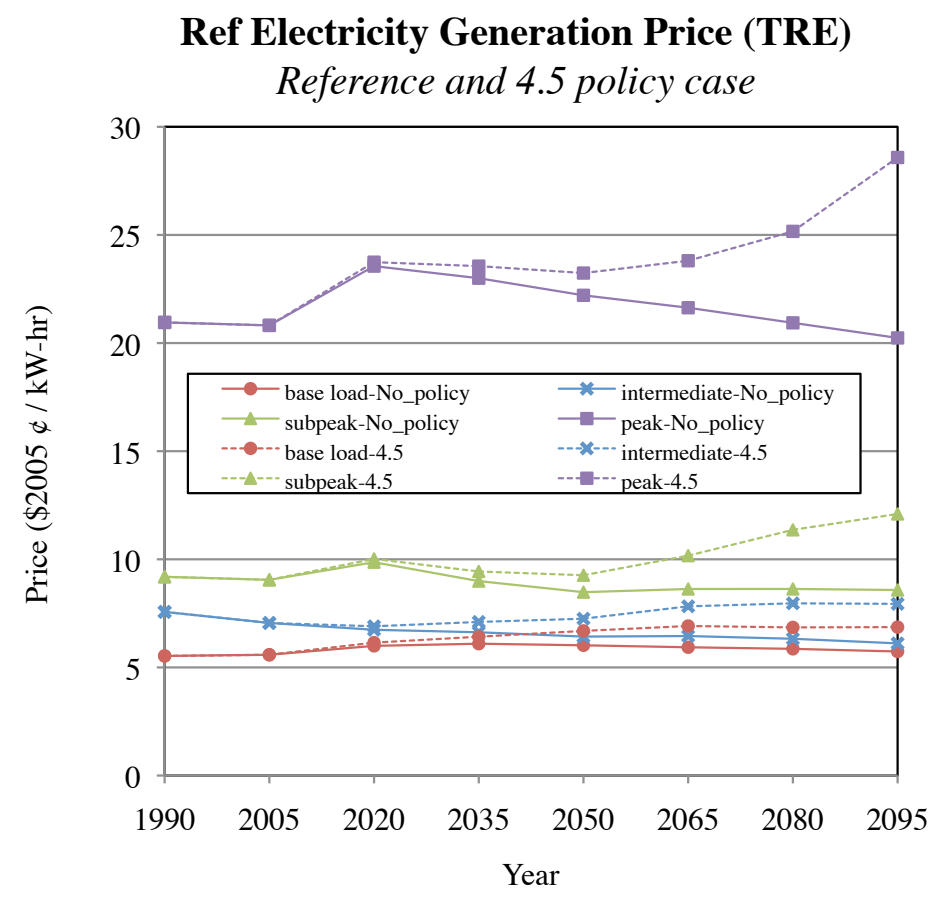

Figure 7. Electricity generation costs in the TRE (Texas) region under the reference and $4.5 \mathrm{~W} / \mathrm{m} 2$ climate policy scenarios.

Note that the cost to the consumer will be a weighted average of the costs for each segment. Changes in electric demand that might reduce the need for peak and sub-peak power was not considered in this study. 


\section{Total Renewable Generation (USA)}

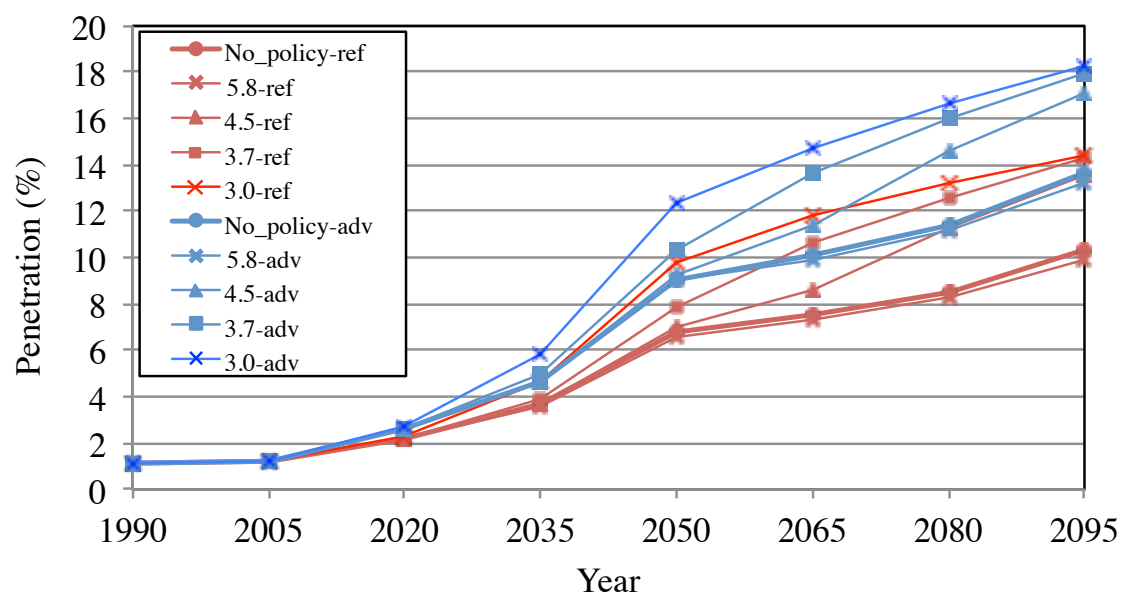

Total Renewable Penetration (USA)

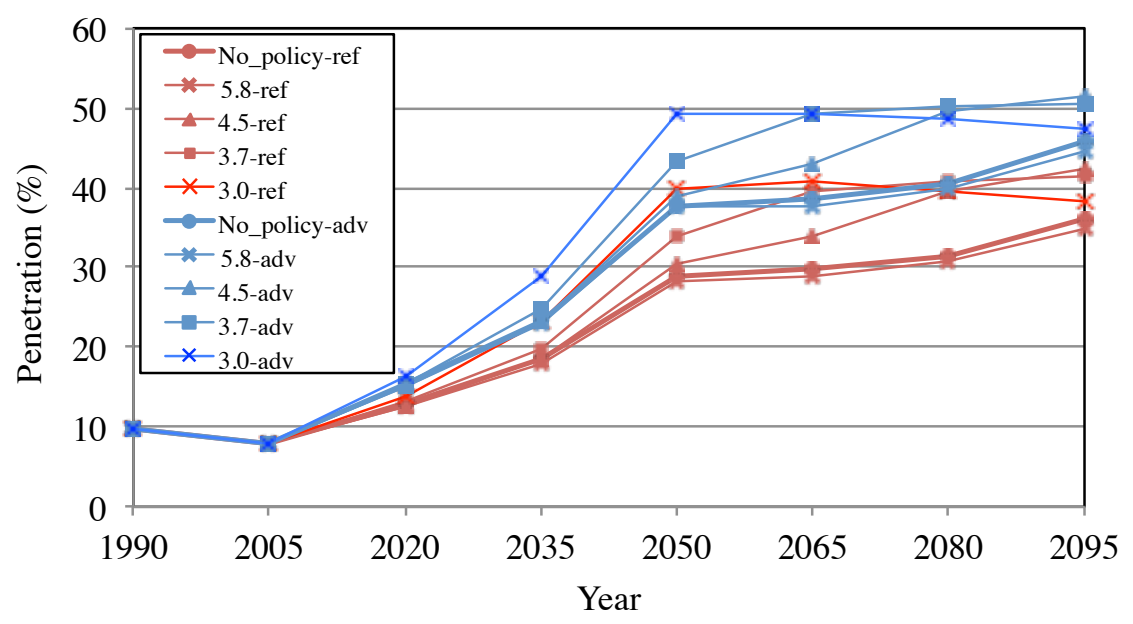

Figure 8. Total U.S. renewable generation, including biomass and hydro power, generation. Absolute value (top) and percentage of total generation (bottom) are shown. Results are shown for reference (thick lines) and policy scenarios, as well as for reference technology (red) and advanced technology (blue) assumptions.

Total renewable generation is shown in Figure 8. Renewable generation increases over time in all scenarios due to both increased electric demand in general and an assumed decrease in renewable technology costs. Renewable generation is higher if the renewable costs are assumed to be smaller, which is the case in the advanced scenario. Renewable generation also increases as the radiative forcing target is lowered. The fraction of U.S. electricity provided by renewables increases over time. The flattening of renewable percentage in some cases is due to model dynamics, particularly competition from other electric generation sources, but also the extent to which the generation profile of renewables can contribute to different generation segments. There is no set limit to renewable penetration in these scenarios. Generation fractions from the no new nuclear or CCS scenarios have generation fractions that are much higher.

U.S. electricity production by technology is shown in Figure 9 for the $4.5 \mathrm{~W} / \mathrm{m} 2$ policy scenario with advanced renewable assumptions. Biomass, CSP, on and off-shore wind, and PV 
make large contribution to U.S. electric generation under this scenario. Biomass generation is particularly important, as biomass coupled with CCS, can provide net negative emissions. Wind, solar, and geothermal supply $33 \%$ of U.S. electric generation in 2095 for this scenario.

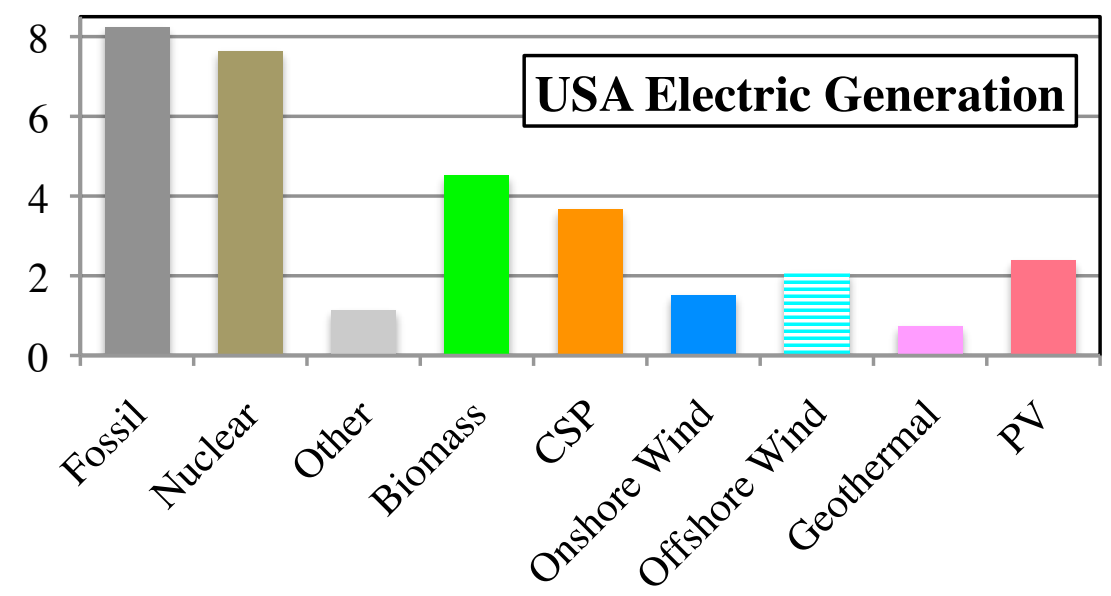

Figure 9. U.S. generation by type in 2095 under the $4.5 \mathrm{~W} / \mathrm{m} 2$ policy case, with advanced assumptions for renewable technologies characteristics.

Figure 10 shows generation by sub-region for the same scenario. The regional generation mix varies considerably. Note that no regional differences in technology preferences or mandates were assumed. The differences shown here are solely due to the different assumptions for regional costs and resources of solar, wind, and geothermal technologies. The relative role of different renewable technologies reflects the regional distribution of renewable resources. The renewable percentage is lowest in the southeast, RFC_West, and RFC_East regions (see Figure 10). The renewable fraction in the mid-west is around $40 \%$, while on the west and southwest, the renewable fraction is around $50 \%$.

CSP solar technologies play the largest role in the west and south west. Offshore wind is largest along the east coast, and on-shore wind plays a larger role in the mid-west. Under a carbon dioxide emissions constraint, regions with abundant renewable resources preferentially use those resources. Those regions without good quality renewable resources rely more heavily on fossil, nuclear, or biomass. The ability, in principle at least, to build fossil, nuclear, or biomass plants in any region is a key flexibility. 


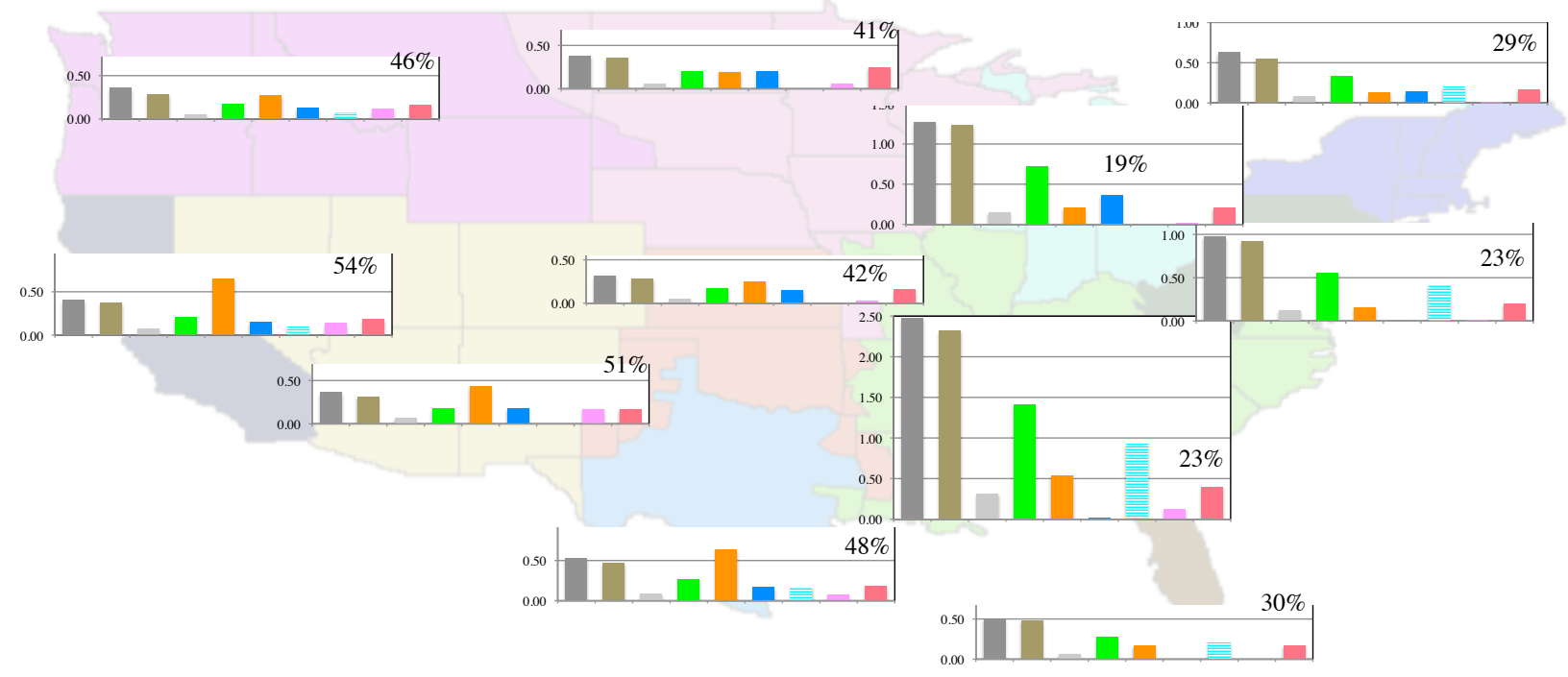

Figure 10. U.S. generation by type and sub-region in 2095 under the $4.5 \mathrm{~W} / \mathrm{m}^{2}$ policy case, with advanced assumptions for renewable technologies characteristics. For legend see Figure 9.The percentage of wind, solar, and geothermal is shown for each sub-region.

\subsection{Impact of national transmission}

In the national grid scenarios, any sub-region can, in addition to regional generation, also consume renewable generation from elsewhere in the United States through a national grid, paying an additional $\sim 1$ cents $/ \mathrm{kWhr}$ along with an additional 5\% transmission loss. Figure 11 shows the impact of a national grid, for the $4.5 \mathrm{~W} / \mathrm{m}^{2}$ scenario assuming advanced renewable technologies. There is an increase in the consumption of CSP and on-shore wind, as these are two of the most competitive technologies, and a decrease in fossil and nuclear generation. Note, however, that these shifts are relatively small compared to total U.S. electricity generation of $\sim 32 \mathrm{EJ}$ in 2095 in this scenario. If no new nuclear or CCS is assumed, then the shifts are twice as large for on-shore wind and 3 times as large for CSP.

Impact of a National Renew Grid 4.5 scenario, Adv Renew Tech, all tech's available

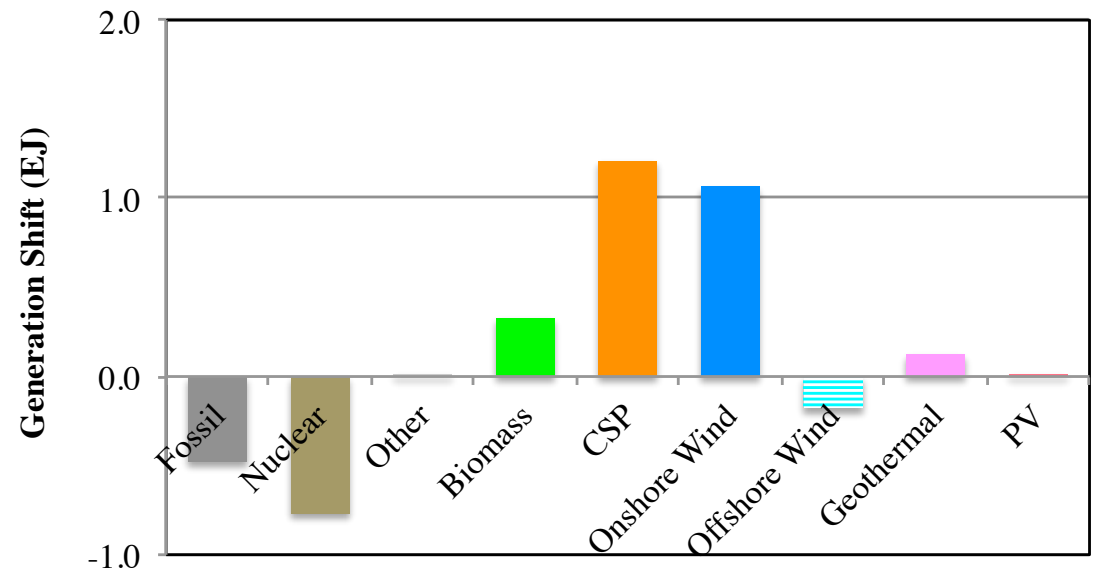


Figure 11. Difference in generation between the regional transmission scenario and the national grid scenario. A positive value means that more generation of that type is used in the national grid scenario.

The intermittency mitigation scenario had very little impact on the results. In this scenario intermittency effects, such as wind and PC curtailment and reserve margin requirements, where evaluated against national renewable penetration levels instead of regional levels. The low impact of this change in assumption may mean that a modeling simplification may be reasonable whereby only national markets instead of multiple regional markets are tracked.

\subsection{Renewable Generation and Climate Policy Costs}

The carbon price for several carbon policy cases is shown in Figure 12. In the original scenario set-up global carbon prices increases at a constant rate over time. When the U.S. carbon constraints are applied using the detailed U.S. regional model, the same basic character is seen. Under the weakest carbon constraint, the reference case using the detailed renewable model is below the carbon constraint until 2065 due to a larger penetration of renewables as compared to the core GCAM model. Renewable generation in this scenario is sufficient to keep reference case emissions below the specified carbon constraint path. The $4.5 \mathrm{~W} / \mathrm{m}^{2}$ case meets the constraint in 2020 , with the carbon price increasing to $500 \$ / \mathrm{tC}$ in 2095 . The two most stringent scenarios $(3.0$ $\mathrm{W} / \mathrm{m}^{2}$ and $3.0 \mathrm{~W} / \mathrm{m}^{2}$ ) reach carbon prices of 1,000 and 2,000 $\$ / \mathrm{tC}$ by 2095.

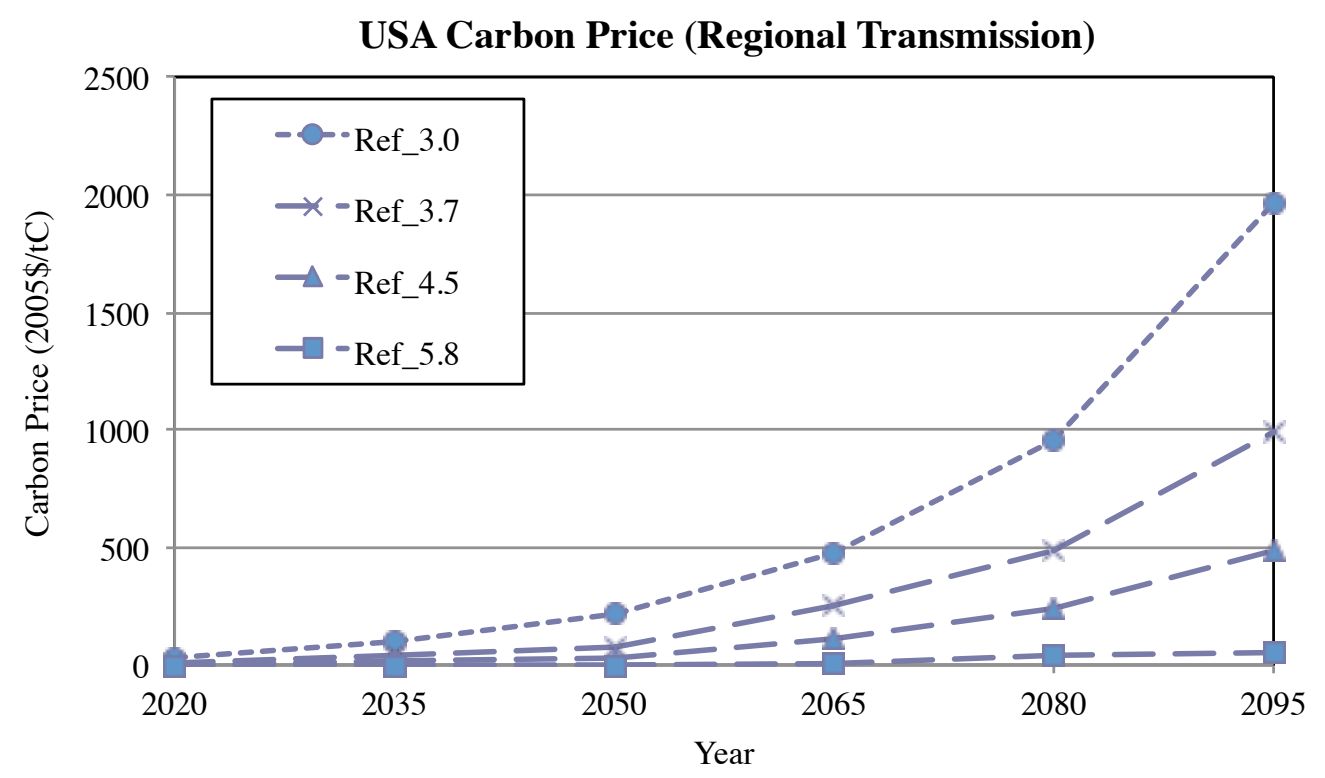

Figure 12. USA carbon price for several climate policy targets under reference technology and regional transmission assumptions.

More important than the absolute values are the changes in carbon prices under a change in assumptions. The table below (rounded to 5\%) shows how the carbon prices change, relative to the reference technology scenario, for several alternatives: advanced renewable technologies, no CCS or New Nuclear, and the national grid scenario. An important general tend is that renewable 
assumptions only impact the results when the carbon prices are under about $\$ 100 / \mathrm{tC}$. Above this level the electricity generation is largely decarbonized and carbon prices depend on the ability of end-use sectors to reduce carbon emissions.

In the early stages of a carbon policy, renewable generation assumptions have a significant impact on carbon prices. More favorable assumptions for renewable technologies across the board, as in the "advanced" renewable technology scenario, lower carbon prices significantly in early years. Note that the relative change in the very first year of a policy can be large due to a low carbon price in that first year. The carbon price in the second policy period is $15-40 \%$ lower under the more favorable "advanced" case assumptions for renewable generation.

Table 3. Carbon Price Change From Reference Technology with Regional Transmission Scenario

\begin{tabular}{|c|c|c|c|c|c|c|}
\hline & 2020 & 2035 & 2050 & 2065 & 2080 & 2095 \\
\hline Adv 5.8 & - & - & - & $-100 \%$ & $-25 \%$ & $-5 \%$ \\
\hline Adv 4.5 & - & $-70 \%$ & $-40 \%$ & $-5 \%$ & $0 \%$ & $0 \%$ \\
\hline Adv 3.7 & $-60 \%$ & $-15 \%$ & $-10 \%$ & $0 \%$ & $0 \%$ & $0 \%$ \\
\hline Adv 3.0 & $-20 \%$ & $-5 \%$ & $0 \%$ & $0 \%$ & $0 \%$ & $0 \%$ \\
\hline Ref 5.8 No CCS or NewNuc & - & - & - & $440 \%$ & $90 \%$ & $100 \%$ \\
\hline Ref 4.5 No CCS or NewNuc & - & $55 \%$ & $80 \%$ & $80 \%$ & $155 \%$ & $210 \%$ \\
\hline Ref 3.7 No CCS or NewNuc & $-10 \%$ & $35 \%$ & $85 \%$ & $160 \%$ & $215 \%$ & $155 \%$ \\
\hline Ref 3.0 No CCS or NewNuc & $0 \%$ & $40 \%$ & $175 \%$ & $225 \%$ & $210 \%$ & $*$ \\
\hline AdvRenew-NoNucCCS 5.8 & - & - & - & $45 \%$ & $45 \%$ & $70 \%$ \\
\hline AdvRenew-NoNucCCS 4.5 & - & $-40 \%$ & $5 \%$ & $55 \%$ & $145 \%$ & $210 \%$ \\
\hline AdvRenew-NoNucCCS 3.7 & $-85 \%$ & $10 \%$ & $50 \%$ & $150 \%$ & $215 \%$ & $160 \%$ \\
\hline AdvRenew-NoNucCCS 3.0 & $-20 \%$ & $25 \%$ & $165 \%$ & $225 \%$ & $215 \%$ & $*$ \\
\hline Natl Grid 5.8 & - & - & - & $-55 \%$ & $-5 \%$ & $0 \%$ \\
\hline Natl Grid 4.5 & - & $-30 \%$ & $-15 \%$ & $0 \%$ & $0 \%$ & $0 \%$ \\
\hline Natl Grid 3.7 & $-35 \%$ & $-5 \%$ & $-5 \%$ & $0 \%$ & $0 \%$ & $0 \%$ \\
\hline Natl Grid 3.0 & $-10 \%$ & $0 \%$ & $0 \%$ & $0 \%$ & $0 \%$ & $0 \%$ \\
\hline
\end{tabular}

Removing the option of building new nuclear plants and the use of carbon-dioxide capture and geologic storage (CCS) increases costs at all periods. Cost increases are particularly large in later years as CCS is a critical technology as it allows emissions reductions in sectors such as refining, and also allows net negative emissions when coupled with combustion of biomass. In early years, the impact of the noNuc-CCS assumption has a somewhat larger relative influence, although of opposite sign, than the advanced renewable assumptions.

Also shown in the table is the combination of advanced renewable assumptions with the assumption of no-new nuclear and no CCS. In the early stages of a climate policy, more favorable renewable assumptions can offset less favorable assumptions for nuclear and CCS. As 
policy emission targets get lower, however, the lack of CCS options increases costs considerably. This is due to the importance of CCS in lowering emissions in sectors such as refining and cement (Luckow et al. 2010), where renewable options were not assumed to be available in these scenarios.

Finally, the presence of a national renewable grid also reduces costs, although by $5-15 \%$ in the second policy period. Allowing renewable energy production to be used in any sub-region, even with a cost penalty, allows sub-regions with limited renewable resources to use, for example, wind from the mid-west or solar from the southwest. Note that such a national grid might have additional benefits in terms of integrating renewables, such as allowing better matching between load and demand on a continental scale, but these benefits could not be evaluated in this framework.

\section{Conclusions}

This project has demonstrated the ability of the GCAM integrated assessment model to simulate renewable electricity generation at a sub-regional level in the United States. Regional renewable resources differ greatly across the United States and adding the ability to consider 12 U.S. sub-regions allows analysis of the impact of these differences. No overall constraints on renewable generation were applied, with the impact of intermittency addressed for each technology.

Renewable generation, including hydro and biomass, comprise a large portion of U.S. electricity supply in these scenarios, supplying 35-50\% of electric generation by the end of the century, even in scenarios allowing competition with a full suite of electric generation technologies. Renewable penetration was highest in the west/south west, and lowest in the east/south-east. Use of renewable generation increases under an economy-wide carbon constraint, and also if future costs of renewable technologies are assumed to be lower and a more flexible electricity system is assumed.

Wind and CSP thermal power are the largest renewable sources. Offshore wind makes a substantial contribution, particularly along the east coast, in the advanced scenario where offshore wind farm transmission and construction costs are assumed to fall more rapidly.

The availability of a national transmission grid can further reduce costs, and changes the generation mix. The presence of a national transmission grid allows greater use of onshore wind and CSP in sub-regions where renewable resources are more limited.

A general finding of integrated energy models is that the electric generation system largely de-carbonizes in the early stages of a comprehensive carbon pricing policy (Clarke et al. 2007). Consistent with this, we find that renewable assumptions have the most impact in the early years of a climate policy, which is where most of the transformation of the electricity system occurs. We demonstrate that renewable electricity generation can provide important flexibility in the lowering costs in the early stages of a climate policy. Climate policy costs in latter years, when 
emissions targets are lower, did not depend on renewable assumptions, but instead on assumptions for the remainder of the energy system, such as low-carbon options in the refining sector and the potential for electric vehicles in the transportation system.

\section{Acknowledgements}

Primary funding for this project was from the U.S. Department of Energy's Office of Energy Efficiency and Renewable Energy, with additional support from the Global Technology Strategy Project and the California Energy Commission. Some methodological descriptions in this report are shared with other reports that use the same model. The authors would like to thank Patrick Luckow for helpful comments on the draft report.

\section{References}

Augustine, C., K.R. Young, and A. Anderson (2010). Updated U.S. Geothermal Supply Curve. Golden, CO: National Renewable Energy Laboratory, NREL/CP-6A247458.

Brenkert, A., Smith, S., Kim, S., Pitcher, H., 2003. Model Documentation for the MiniCAM. PNNL-14337, Pacific Northwest National Laboratory, Richland WA.http://www.pnl.gov/main/publications/external/technical_reports/PNNL-14337.pdf

Christensen, C. and G. Barker (1998). "Annual System Efficiencies for Solar Water Heating." Proc. ASES, ASES, Boulder, CO.

Clarke, J,F and Edmonds, J.A., 1993. Modeling energy technologies in a competitive market. Energy Economics 15, 123-129.

Clarke, L., J. Edmonds, H. Jacoby, H. Pitcher, J. Reilly, and R. Richels (2007). Scenarios of Greenhouse Gas Emissions and Atmospheric Concentrations. Sub-report 2.1A of Synthesis and Assessment Product 2.1 by the U.S. Climate Change Science Program and the Subcommittee on Global Change Research. Washington, D.C.: U.S. Department of Energy, Office of Biological \& Environmental Research.

Clarke, L., Weyant, J., Edmonds, J., 2008b. On sources of technological change: what do the models assume? Energy Economics 30, 409-424.

Clarke, L., Wise, M.A., Edmonds, J., Placet, M., Kyle, P., Calvin, K., Kim, S., Smith, S., $2008 b$. $\mathrm{CO}_{2}$ Emissions Mitigation and Technological Advance: an Updated Analysis of Advanced Technology Scenarios (Scenarios Updated January 2009). PNNL-18075, Pacific Northwest National Laboratory, Richland, WA. http://www.pnl.gov/science/pdf/PNNL18075.pdf

Denholm, P. and R. Margolis (2007a). "Evaluating the limits of solar photovoltaics (PV) in traditional electric power systems." Energy Policy 35: 2852-2861.

Denholm, P. and R. Margolis (2007b). "Evaluating the limits of solar photovoltaics (PV) in electric power systems utilizing energy storage and other enabling technologies." Energy Policy 35: 4424-4433. 
Denholm, P., and R. Margolis (2008). Supply curves for rooftop PV-generated electricity for the United States. Golden, CO: National Renewable Energy Laboratory, NREL/TP-6AO44073.

EnerNex Corporation. 2010a. Eastern Wind and Solar Integration Study. NREL/SR-550- 47078. Golden, CO: National Renewable Energy Laboratory

EnerNex Corporation. 2010b. Nebraska Statewide Wind Integration Study. NREL/SR-55047519. Golden, CO: National Renewable Energy Laboratory

GE Energy. 2010. Western Wind and Solar Integration Study. NREL/SR-550-47434. Golden, CO: National Renewable Energy Laboratory

Green, J., A. Bowen, L.J. Fingersh, and Y. Wan (2007). Electrical Collection and Transmission Systems for Offshore Wind Power. Golden, CO: National Renewable Energy Laboratory, NREL/CP-500-41135.

Greenacre, P., R. Gross, and P. Heptonstall (2010). Great Expectations: The cost of offshore wind in UK waters - Understanding the past and projecting the future. London: UK Energy Research Centre, ISBN 1903144094.

Hannam, P., P. Kyle, and S.J. Smith (2009). Global Deployment of Geothermal Energy Using a New Characterization in GCAM 1.0. College Park, MD: Battelle Memorial Institute, PNNL-19231.

Hoogwijk, M., de Vries, B., Turkenburg, W., 2004. Assessment of the global and regional geographical, technical and economic potential of onshore wind energy. Energy Economics 26, 889-919.

Hoppock, D.C. and D. Patino-Echeverri, 2010. Cost of Wind Energy: Comparing Distant Wind Resources to Local Resources in the Midwestern United States. Environmental Science \& Technology 40, 8758-8765.

Kim, S., Edmonds, J., Lurz, J., Smith, S., Wise, M., 2006. The Object-oriented Energy Climate Technology Systems (ObjECTS) framework and hybrid modeling of transportation in the MiniCAM long-term, global integrated assessment model. The Energy Journal, Special Issue: Hybrid Modeling of Energy-Environment Policies: Reconciling Bottom-up and Top-down, 63-91.

Kyle, P., S.J. Smith, M.A. Wise, J.P. Lurz, and D. Barrie (2007). Long-Term Modeling of Wind Energy in the United States. College Park, MD: Battelle Memorial Institute, PNNL16316.

Luckow P, MA Wise, JJ Dooley, and SH Kim. 2010. "Large-Scale Utilization of Biomass Energy and Carbon Dioxide Capture and Storage in the Transport and Electricity Sectors under Stringent CO2 Concentration Limit Scenarios." International Journal of Greenhouse Gas Control 4(5):865-877. doi:10.1016/j.ijggc.2010.06.002

Lund, H. and W. Kempton, 2008. Integration of renewable energy into the transport and electricity sectors through V2G. Energy Policy, doi:10.1016/j.enpol.2008.06.007

Musial, W. and S. Butterfield (2004). Future for Offshore Wind in the United States. Golden, CO: National Renewable Energy Laboratory, NREL/CP-500-36313. 
U.S. DOE, 2008. 20 percent Wind Energy by 2020, Increasing Wind Energy's Contribution to U.S. Electricity Supply. DOE/GO-102008-2567. Office of Energy Efficiency and Renewable Energy, U.S. Department of Energy, Washington, D.C. http://www1.eere.energy.gov/windandhydro/pdfs/41869.pdf

Wise, M.A., and S.J. Smith, 2007. Integrating Renewable Electricity, Electricity Demand, and Electricity Storage: A New Approach for Modeling the Electricity Sector in ObjECTS PNNL-16500.

Zhang, Y., and S.J. Smith (2007). Long-Term Modeling of Solar Energy: Analysis of PV and CSP Technologies. PNNL-16727.

Zhang, Y., S.J. Smith, G.P. Kyle, and P.W. Stackhouse Jr. (2010). "Modeling the Potential for Thermal Concentrating Solar Power Technologies”. Energy Policy 38: 7884-7897. 